\title{
Effects of Fengliao-Changweikang in Diarrhea- predominant Irritable Bowel Syndrome Rats and Its Mechanism Involving Colonic Motility
}

\author{
Mengdi Jia, Xiaofang Lu, Zhengfang Wang, Luqing Zhao, and Shengsheng Zhang* \\ Digestive Disease Center, Beijing Hospital of Traditional Chinese Medicine Affiliated to Capital Medical University, Beijing, China
}

\begin{abstract}
Background/Aims
This study was designed to investigate the effect of Fengliao-Changweikang (FLCWK) in diarrhea-predominant irritable bowel syndrome (IBS-D) rats and explore its underlying mechanisms.

\section{Methods}

IBS-D model rats were induced by neonatal maternal separation (NMS) combined with restraint stress (RS). In in vivo experiments, the model rats were randomly divided into 5 groups: NMS + RS, FLCWK (low dose, middle dose, and high dose), and pinaverium bromide. The normal control (no handling) rats were classified as the NH group. The therapeutic effect of FLCWK was evaluated by fecal characteristics, electromyographic response and abdominal withdrawal reflex scores. In in vitro experiments, the model rats were randomly divided into 2 groups: NMS + RS, FLCWK (middle dose), and no handling rats were used as the NH group. The differences in basic tension and ACh-induced tension of isolated colonic longitudinal smooth muscle strips (CLSMs) among the 3 groups were observed. In addition, different inhibitors (nifedipine, TMB-8, L-NAME, methylene blue, and 4-AP) were pretreated to explore the underlying mechanisms.
\end{abstract}

\section{Results}

In in vivo experiments, fecal characteristics, electromyographic response, and abdominal withdrawal reflex scores significantly improved in the FLCWK group, compared with the NMS + RS group. In in vitro experiments, the basic tension and ACh-induced tension of CLSMs in IBS-D rats were significantly inhibited by FLCWK. After pre-treatment with different inhibitors, the ACh-induced tension of CLSMs in each group showed no significant difference.

\section{Conclusions}

FLCWK manifested curative effect in IBS-D rats by inhibiting colonic contraction. The underlying mechanisms may be related to regulatory pathway of nitric oxide/cGMP/ $\mathrm{Ca}^{2+}$ and specific potassium channels.

(J Neurogastroenterol Motil 2018;24:479-489)

\section{Key Words}

Gastrointestinal motility; Herbal medicine; Irritable bowel syndrome; Nitric oxide; Potassium channels

Received: July 28, 2017 Revised: October 21, 2017 Accepted: November 20, 2017

(.) This is an Open Access article distributed under the terms of the Creative Commons Attribution Non-Commercial License (http://creativecommons. org/licenses/by-nc/4.0) which permits unrestricted non-commercial use, distribution, and reproduction in any medium, provided the original work is properly cited.

*Correspondence: Shengsheng Zhang, MD

Digestive Disease Center, Beijing Hospital of Traditional Chinese Medicine Affiliated to Capital Medical University, 23

Meishuguanhou Street, Beijing, China

Tel: +86-010-52176634, Fax: +86-010-52176634,E-mail: zhss2000@163.com 


\section{Introduction}

Irritable bowel syndrome (IBS) is a functional bowel disease in which recurrent abdominal pain is associated with defecation or a change in bowel habits. IBS is classified into 3 main subtypes according to the predominant disorder in bowel habits: constipationpredominant IBS (IBS-C), diarrhea-predominant IBS (IBS-D), and mixed IBS (IBS-M) in Rome IV. ${ }^{1}$ According to a meta-analysis, IBS has a high prevalence of $11.2 \%$ all over the world. ${ }^{2}$ As one of the most frequent subtypes of IBS patients, the IBS-D patients have lower quality of life than the other subtypes. ${ }^{3,4}$

Multifactor effects have been reported to be involved in the pathogenesis of IBS-D, however, it has not been well understood until now. Therefore, although a number of therapeutic options have been developed to treat this disease, such as loperamide, bile salt sequestrants, opioid agonists, and 5-hydroxytryptamine 3 antagonists, the clinical effectiveness has not been satisfactory for both patients and market demand. Despite evidence that those drugs benefit the treatment of IBS in the short term, there is no medical intervention proven to alter the long-term natural history of this condition. $^{5-9}$ Furthermore, there is limited evidence of the efficacy, safety and tolerability of these therapies currently available for the treatment of IBS. ${ }^{10-12}$

Presently, more and more randomized controlled trials have demonstrated that Traditional Chinese Medicine, for instance the patent drug Fengliao-Changweikang (FLCWK) can significantly relieve the symptoms as well as improve the quality of life in IBS-D patients. ${ }^{13,14}$ FLCWK, a multi-ingredient Chinese patent medicine, is composed of Daphniphyllum calycinum and Polygonum hydropiper, which play vital roles in clearing heat, de-humidificating, and relieving stagnation to improve symptoms of abdominal pain and diarrhea for patients with IBS-D. According to modern pharmacological studies, the chemical constituents of FLCWK are mainly composed of sesquiterpenoids, quercetin, rutin, hyperin, flavonoid, alkaloids, and organic acids contributing to clinical efficacy. ${ }^{15,16}$ However, the mechanism of the therapeutic effect has not been well studied, which limits the application of FLCWK on a larger scale.

Accordingly, the present study aim to investigate the effects of FLCWK in rat model of IBS-D and study the underlying mechanisms involving colonic motility.

\section{Materials and Methods}

\section{Animals}

Sprague-Dawley male rats (postnatal day 1) were obtained from Vital River Laboratories Animal Technology Co, Ltd (Beijing, China), and kept in Dongzhimen Hospital Affiliated to Beijing University of Chinese Medicine. All rats were housed in a standardized environment at a temperature $\left(21-23^{\circ} \mathrm{C}\right)$ and humidity $(50$ $\pm 5 \%$ ) with a 12-hour light/dark cycle (lights on at $8 \mathrm{AM}$ ), and had access to food and water ad libitum. In the present study, female rats were excluded to eliminate the possible effects of estrogen or the other female hormones on the secretory and sensory responses in the intestine. ${ }^{17}$ All manipulations were performed between 8 $\mathrm{AM}$ and $11 \mathrm{AM}$ every day to minimize the influence of circadian rhythms. On postnatal day 22, all the litters were weaned and kept in the individual cages with 3-4 pups per cage.

The study was performed according to the institutional ethical guidelines and conformed to the requirements of the Institutional Animal Care and Use Committee of Beijing University of Chinese Medicine. All animal cares and experimental procedures were approved by the Animal Ethics Committee of Dongzhimen Hospital Affiliated to Beijing University of Chinese Medicine (No. 16-10).

\section{Induction of Diarrhea-predominant Irritable Bowel Syndrome in Rats}

On postnatal days 2-21, the neonatal maternal separation (NMS) was conducted as previously described. ${ }^{18-20}$ The NMS + restraint stress (RS) litters were removed from their home cages and separated from their maternal rats for 3 hours each day. The litters were placed alone in a separated cage maintained at $23 \pm 0.5^{\circ} \mathrm{C}$ by a thermally regulated facility during the period of isolation. The litters were replaced into their home cages immediately after separation. The normal control litters remained in their home cages with their maternal rats all the time.

On postnatal days 50-59, the restraint stress was performed as follows. ${ }^{21,22}$ the NMS + RS rats were placed in a transparent plastic restraint cylinder $\left(4 \times 4 \times 18 \mathrm{~cm}^{3}\right)$ for 3 hours, in which they could move forward and backward but could not turn around.

\section{In Vivo Experiments}

\section{Drugs and administration}

Fengliao-Changweikang (batch number: 140501; Haikou 
Pharmaceutical Co, Ltd, Hainan, China). According to the equivalent dose-ratio table of human and animal body surface area: the dosage of the rats $=\mathrm{X} \mathrm{mg} / \mathrm{kg} \times 70 \mathrm{~kg} \times 0.018 / 0.2 \mathrm{~kg}(\mathrm{X}$ is the adult clinical dosage). ${ }^{23,24}$

The normal control (no handling) rats were classified as the $\mathrm{NH}$ group, NMS + RS rats were divided into 5 groups: NMS + RS; low dose group: FLWCK 1.125 mg/100 g; middle dose group: FLWCK $2.25 \mathrm{mg} / 100 \mathrm{~g}$; high dose group: FLWCK 4.5 $\mathrm{mg} / 100 \mathrm{~g}$; and the positive control group: pinaverium bromide 1.5 $\mathrm{mg} / 100 \mathrm{~g}$. From postnatal day 60, the rats in the FLCWK group and positive control group were given intragastric administration with treatment, respectively; the NH group and NMS + RS group were given distilled water. All groups were treated for 14 consecutive days.

\section{The fecal indexes}

The feaces in all 6 groups of rats were collected 24 hours after treatment of 14 days. Collected feces were calculated and weighed immediately (wet), and again after drying for 10 hours at $80^{\circ} \mathrm{C}$ (dry). The fecal water content was calculated as the following formula:

Fecal water content $(\%)=[($ wet feces - dry feces $) /$ wet feces $]$ $\times 100$

\section{Measurement of visceral hypersensitivity}

After 14 days of the treatment, the abdominal withdrawal reflex (AWR) scoring system and electromyographic (EMG) activity of the external oblique muscle were used to evaluate visceral hypersensitivity. ${ }^{25}$ The rats were deeply inhalational anesthetized by isofurane, then a flexible balloon (length of about $5 \mathrm{~cm}$, the maximum volume of about $10 \mathrm{~mL}$; serial number C75774; Mui Scientific, Mississauga, Canada) with a matched tube was inserted from anus to descending colon and fixed in place by sticking the tubing to the tail. Rats were placed in a cage and allowed to adapt for 30 minutes. CRD was simulated by rapidly inflating the balloon to a constant pressure, and the pressure of the balloon was increased stepwise, 20, 40,60 , and $80 \mathrm{mmHg}$ with duration of 30 seconds and at an interval of 180 seconds between distensions.

Recording the EMG activity of the external oblique muscle to calculate the ratio which is the pressure period integral divided by the baseline integral to evaluate the EMG response to CRD. The AWR score presenting the behavioral responses to CRD was observed and evaluated by a researcher blinded to the treatment protocol. The assignment of an AWR score was as follows: $1=$ normal behavior without response; $2=$ contraction of abdominal muscles;
$3=$ lifting of abdominal wall; and $4=$ body arching and lifting of pelvic structures. ${ }^{26}$

\section{In Vitro Experiments}

\section{Reagents and apparatuses}

The Krebs-Henseleit solution used in the experiment was composed of the following reagents: $117 \mathrm{mmol} / \mathrm{L} \mathrm{NaCl}, 4.7 \mathrm{mmol} /$ $\mathrm{L} \mathrm{KCl}, 1.2 \mathrm{mmol} / \mathrm{L} \mathrm{MgCl}_{2}, 24.8 \mathrm{mmol} / \mathrm{L} \mathrm{NaHCO}, 1.2 \mathrm{mmol} / \mathrm{L}$ $\mathrm{KH}_{2} \mathrm{PO}_{4}, 2.56 \mathrm{mmol} / \mathrm{L} \mathrm{CaCl}_{2}$, and $11.1 \mathrm{mmol} / \mathrm{L}$ glucose

The following were used: acetylcholine (ACh), batch number: A6625; nifedipine, batch number: N-7634; 8-(diethylamino)-octyl3,4,5-trimethoxybenzoate hydrochloride (TMB-8), batch number: T111; 4-aminopyridine (4-AP), batch number: 275875; methylene blue, batch number: M9140; and $\mathrm{N} \omega$-nitro-L-arginine methyl (L-NAME), batch number: N5751. All of the reagents were purchased from Sigma-Aldrich (St Louis, MO, USA).

The CH-1015 super thermostatic bath was from Shanghai Yueping Scientific Instrument Co, Ltd, Shanghai, China. Flowing apparatus was from AD Instruments, Castle Hill, Australia: MLT02021D external isometric force transducer, PL 3508-0028 four-channel recorder, ML 0146/C-V Panlab Four-Chamber Organ Bath, ML110 Powerlab amplifier, and Power Lab/4SP data processing and analysis system.

\section{Tissue preparation}

The modeling method as described above, the normal control (no handling) rats were classified as the NH group; NMS + RS rats in the 2 groups: NMS + RS group; NMS + RS plus FLWCK group: $2.25 \mathrm{mg} / 100 \mathrm{~g}$ (The dose of the FLCWK was depended on the previous experiments), the NH group and NMS $+\mathrm{RS}$ group were given distilled water. After 14 days of treatment, all rats were killed with the method of cervical dislocation. The distal colon (6-7 cm from the anus) was quickly taken and incised longitudinally along the mesenteric border. Muscle strips $(0.8 \mathrm{~cm}$ $\times 0.2 \mathrm{~cm}$ ) cut parallel to longitudinal fibers of the colon, each strip with the mucosa and submucosa was carefully removed by scissors and fine forceps, and then suspended in a tissue chamber containing $15 \mathrm{~mL}$ Krebs solution. ${ }^{27}$ Both ends of each muscle strip were knotted by a medical thread. One end of the strip was fixed to the bottom of the bath with the other connected to a physiological recorder through the tonotransducer. Strips of the initial load were 1 $\mathrm{g}(2 \mathrm{mV})$ to maintain basic tension. Each muscle strip was mounted in organ baths $(15 \mathrm{~mL})$ filled with Kreb's solution, maintained at $37^{\circ} \mathrm{C}$ and circulated continuously with $95 \% \mathrm{O}_{2}$ and $5 \% \mathrm{CO}_{2}$. The 
strips were allowed to equilibrate for 60 minutes with fresh Kreb's solution at 15 -minute intervals before the experiment. ${ }^{28}$ The following experiments were performed using 6 rats in each group with each pretreatment drug,

\section{Effects of Fengliao-Changweikang on the Basic Tension and Acetylcholine-induced Tension}

The strips of 3 groups (the number of strips in each group is 6) were subjected to $1 \mathrm{~g}$ load tension and washed with $15 \mathrm{~mL}$ Krebs solution every 15 minutes. After equilibrating for 1 hour to get a basic contraction, contraction was then recorded after $\mathrm{ACh} 10^{-4} \mathrm{~mol} /$ $\mathrm{L}$ was added. The basic tension and ACh-induced tension were compared among the 3 groups to confirm the mechanism involving colonic motility of FLCWK.

\section{Effects of Fengliao-Changweikang on Acetylcholine-induced Tension After Treatment With Nifedipine or TMB-8}

Strips of 3 groups $(n=6)$ were incubated with nifedipine (inhibitor of L-type voltage-depended $\mathrm{Ca}^{2+}$ channel, $10 \mu \mathrm{mol} / \mathrm{L}$ ) for 20 minutes, then $10^{-4} \mathrm{~mol} / \mathrm{L} \mathrm{ACh}$ was added to induce the abnormal contraction of CLSMs. In another experiment, strips in each group ( $\mathrm{n}=6$ ) were incubated with TMB-8 (intracellular calcium antagonist, $20 \mu \mathrm{mol} / \mathrm{L}$ ) for 20 minutes, then $10^{-4} \mathrm{~mol} / \mathrm{L} \mathrm{ACh}$ was added to induce the abnormal contraction of CLSMs. The above method in order to confirm the role of $\mathrm{Ca}^{2+}$ in the therapeutical effect of FLCWK.

\section{Effects of Fengliao-Changweikang on Acetylcholine-induced Tension After Treatment With L-NAME or Methylene Blue}

Strips of 3 groups $(n=6)$ were incubated with L-NAME (inhibitor of nitric oxide synthase, $10^{-4} \mathrm{~mol} / \mathrm{L}$ ) for 20 minutes, then contraction of CLSMs in each group added to $10^{-4} \mathrm{~mol} / \mathrm{L} \mathrm{ACh}$ were measured. Or in another experiment, methylene blue (inhibitor of guanylate cyclase, $10 \mu \mathrm{mol} / \mathrm{L}$ ) was added to strips in each group $(n=6)$ for 20 minutes, then contraction of CLSMs in each group added to $10^{-4} \mathrm{~mol} / \mathrm{L} \mathrm{ACh}$ were measured. Various inhibitors were pretreated to check if the nitric oxide (NO)/cGMP pathway was involved in FLCWK's effect.

\section{Effect of Fengliao-Changweikang on Acetylcholine- induced Tension After Treatment With 4-AP}

4-AP $(50 \mu \mathrm{mol} / \mathrm{L})$ was added to strips of 3 groups $(\mathrm{n}=6) 20$ minutes, then $10^{-4} \mathrm{~mol} / \mathrm{L} \mathrm{ACh}$ was added to induce the abnormal contraction of CLSMs. The ACh-induced tension in each group was recorded to compare difference, verifying the importance of $\mathrm{K}^{+}$ channel in the therapeutical effect of FLCWK.

\section{Statistical Methods}

The statistical analyses were performed by using SPSS 17.0 software (IBM, Armonk, NY, USA) and each value was expressed as means \pm SEM. All the original data in the study were distributed normally and conformed to homogeneity of variance. The differences among the 3 groups were analyzed using one-way analysis of variance (ANOVA) followed by least-significant difference test to compare the differences between 2 groups. $P<0.05$ was considered statistically significant.

\section{Results}

\section{Effect of Fengliao-Changweikang on Fecal Indexes in Diarrhea-predominant Irritable Bowel Syndrome Rats}

To confirm successful establishment of the rat model of IBS$\mathrm{D}$ and subsequently to evaluate the effect of treatment, wet feces weight, total number of fecal pellets and water content of the feces in the experimental IBS models were measured. ${ }^{29,30}$ There were significant differences in the wet feces weight, total number of fecal pellets and fecal water content among each group $(\mathrm{n}=8, P<0.05)$. The wet feces weight, total number of fecal pellets and fecal water content in the NMS + RS group was increased compared with the $\mathrm{NH}$ group ( $\mathrm{n}=8, P<0.01$ ). These results suggested that the model of IBS-D was established successfully. ${ }^{29,31}$ After the treatment, the wet feces weight, total number of fecal pellets and fecal water content in the FLCWK group, and the pinaverium bromide group were reduced more than that in the NMS $+\mathrm{RS}$ group $(\mathrm{n}=$ 8, wet feces weight: drug groups: $P<0.05$; total number of fecal pellets: high dose group, middle dose group, pinaverium bromide group: $P<0.01$, low dose group: $P<0.05$; fecal water content: high dose group, middle dose group, pinaverium bromide group: $P<0.01$, low dose group: $P<0.05)$. Furthermore, there was no statistical difference in fecal indexes between the drug groups and the $\mathrm{NH}$ group ( $\mathrm{n}=8, P>0.05$ ), except the low dose group (n $=8$, total number of fecal pellets: $P<0.05$; fecal water content: $P$ $<0.05)$. Thus it was demonstrated that the symptoms of IBS-D model were improved effectively by FLCWK (Table 1). 
Table 1. Effect of Fengliao-Changweikang on the Fecal Indexes

\begin{tabular}{llclc}
\hline \multicolumn{1}{c}{ Group } & $\mathrm{n}$ & Wet feces weight $(\mathrm{g})$ & Fecal pellets $(\mathrm{n})$ & Fecal water content $(\%)$ \\
\hline NH & 8 & $8.40 \pm 0.37$ & $19.25 \pm 1.01$ & $17.53 \pm 1.73$ \\
NMS + RS & 8 & $10.20 \pm 0.35^{\mathrm{a}}$ & $27.88 \pm 1.16^{\mathrm{a}}$ & $32.43 \pm 1.59^{\mathrm{a}}$ \\
High dose & 8 & $8.92 \pm 0.39^{\mathrm{d}}$ & $22.00 \pm 1.46^{\mathrm{c}}$ & $22.51 \pm 2.61^{\mathrm{c}}$ \\
Middle dose & 8 & $9.02 \pm 0.36^{\mathrm{d}}$ & $22.63 \pm 1.31^{\mathrm{c}}$ & $22.31 \pm 2.47^{\mathrm{c}}$ \\
Low dose & 8 & $9.18 \pm 0.31^{\mathrm{d}}$ & $23.38 \pm 1.38^{\mathrm{b}, \mathrm{d}}$ & $24.14 \pm 1.63^{\mathrm{b}, \mathrm{d}}$ \\
Pinaverium bromide & 8 & $8.90 \pm 0.33^{\mathrm{d}}$ & $22.50 \pm 1.31^{\mathrm{c}}$ & $22.01 \pm 2.84^{\mathrm{c}}$ \\
\hline
\end{tabular}

${ }^{a} P<0.01,{ }^{b} P<0.05$, versus the normal control (no handling $[\mathrm{NH}]$ ) group.

${ }^{c} P<0.01,{ }^{\mathrm{d}} P<0.05$, versus the neonatal maternal separation (NMS) + restraint stress (RS) group.

Data are expressed as the mean $\pm \mathrm{SE}(\mathrm{n}=8$ rats/group).

A

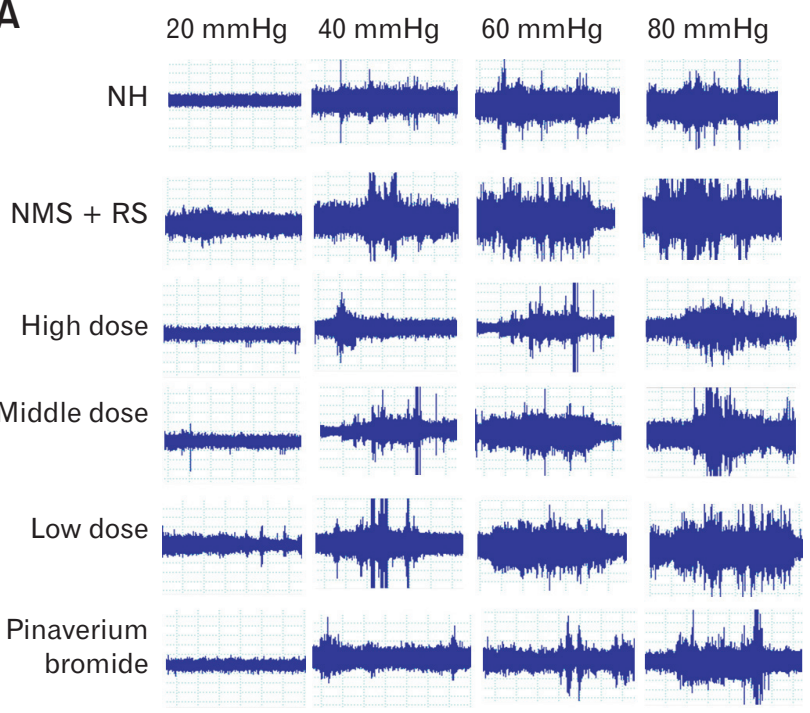

B

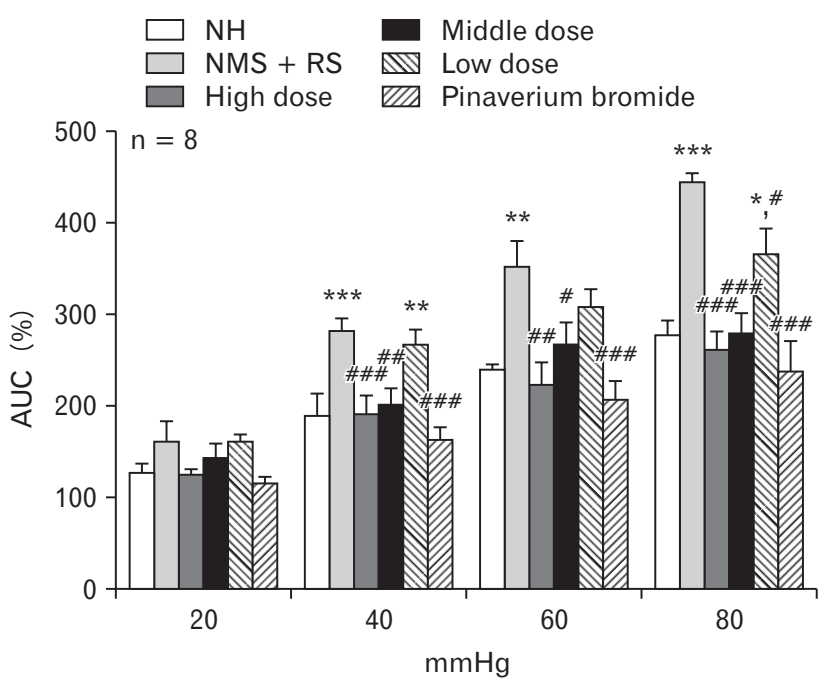

Figure 1. Magnitude of visceromotor response to colorectal distention (CRD) in 6 groups. (A) Typical electromyographic (EMG) tracings of the 6 groups. (B) Effect of Fengliao-Changweikang (FLCWK) on the area under the curve (AUC) (means $\pm \mathrm{SE}, \mathrm{n}=8$ ). ${ }^{*} P<0.05, * * P<0.01$, ${ }^{* * *} P<0.001$ versus normal control (no handling $[\mathrm{NH}]$ ) group; ${ }^{\#} P<0.05,{ }^{\# \#} P<0.01$, ${ }^{\# \#} P<0.001$ versus neonatal maternal separation $(\mathrm{NMS})+$ restraint stress (RS) group.

\section{Effect of Fengliao-Changweikang on the Visceral Hypersensitivity in Diarrhea-predominant Irritable Bowel Syndrome Rats}

\section{Electromyographic recordings (area under the curve)}

Behavioral responses to $\mathrm{CRD}$ were evaluated by a measurement of the EMG activity of the external oblique. ${ }^{16}$ There was no significant difference in EMG activities among the groups $(\mathrm{n}=8$, $P>0.05$; Fig. 1B), when the distention pressure was $20 \mathrm{mmHg}$. However, the EMG activities were statistically different among the groups at distention pressures of 40,60, and $80 \mathrm{mmHg}$ (n $=8, P$ $<0.05$; Fig. 1B). The EMG responses to CRD in the NMS + $\mathrm{RS}$ group were higher than the NH group ( $\mathrm{n}=8 ; 40 \mathrm{mmHg}$ and
$80 \mathrm{mmHg}, P<0.001 ; 60 \mathrm{mmHg}, P<0.01$; Fig. 1B). These data indicated that the NMS + RS group were more sensitive to $\mathrm{CRD}$ compared with the $\mathrm{NH}$ group, suggesting that neonatal maternal separation plus restraint stress (NMS + RS) produced a persistent visceral hypersensitivity in IBS-D rats.

After treatment, the EMG responses in the FLCWK group, and the pinaverium bromide group were significantly lower than the $\mathrm{NH}$ group ( $\mathrm{n}=8$; high dose group: $40 \mathrm{mmHg}$ and $80 \mathrm{mmHg}$, $P<0.001$; $60 \mathrm{mmHg}, P<0.01$; middle dose group: $40 \mathrm{mmHg}$, $P<0.01 ; 60 \mathrm{mmHg}, P<0.05 ; 80 \mathrm{mmHg}, P<0.001$; low dose group: $80 \mathrm{mmHg}, P<0.05$; pinaverium bromide group: 40, 60, and $80 \mathrm{mmHg}, P<0.001$; Fig. 1B). Compared with the $\mathrm{NH}$ group, no significant difference was found in EMG scores among the treatment group $(\mathrm{n}=8, P>0.05$; Fig. 1B), excluding the low 
dose group for $40 \mathrm{mmHg}$ and $80 \mathrm{mmHg}$ distention pressure ( $\mathrm{n}=$ 8; $40 \mathrm{mmHg}, P<0.01 ; 80 \mathrm{mmHg}, P<0.05$; Fig. 1B). These data showed that FLCWK treatment produced persistent visceral hypersensitivity in IBS-D rats.

\section{Abdominal withdrawal reflex scores}

Visceral hypersensitivity was also measured by grading behavioral response of rats to $\mathrm{CRD}$ as described previously. ${ }^{17}$ There was no statistical difference in AWR scores among the groups for $20 \mathrm{mmHg}$ distention pressure $(\mathrm{n}=8, P>0.05)$. However, when the distention pressure was 40,60 , and $80 \mathrm{mmHg}$, the AWR scores were significantly different among the groups ( $\mathrm{n}=8, P<$ $0.05)$. The AWR scores of the NMS + RS group were increased compared with the NH group $(\mathrm{n}=8 ; 40 \mathrm{mmHg}, P<0.01 ; 60$ $\mathrm{mmHg}$ and $80 \mathrm{mmHg}, P<0.05)$. After intervention, the AWR scores for 40, 60, and $80 \mathrm{mmHg}$ distention pressure was significantly reduced among the middle and high dose groups, and the pinaverium bromide group ( $\mathrm{n}=8, P<0.05$ ). In addition, there was no significant difference in AWR scores between the drug groups and the NH group ( $\mathrm{n}=8, P>0.05$ ), except for the low dose group for $60 \mathrm{mmHg}$ and $80 \mathrm{mmHg}$ distention pressure ( $\mathrm{n}=$ $8, P<0.05)$ (Table 2$)$.

\section{Effect of Fengliao-Changweikang on Colonic Contraction in Diarrhea-predominant Irritable Bowel Syndrome Rats}

\section{Fengliao-Changweikang inhibits basic tension and acetylcholine-induced tension}

There were significant differences in basic tension and AChinduced tension of CLSMs between the NH group and the NMS + RS group ( $\mathrm{n}=6$; basic tension, $P<0.001$; ACh-induced tension, $P<0.05$; Fig. 2). After treatment with FLCWK, basic tension and ACh-induced tension of CLSMs in the FLCWK group

Table 2. Effect of Fengliao-Changweikang on the Abdominal Withdrawal Reflex Scores

\begin{tabular}{lccccc}
\hline \multicolumn{1}{c}{ Group } & $\mathrm{n}$ & $20 \mathrm{mmHg}$ & $40 \mathrm{mmHg}$ & $60 \mathrm{mmHg}$ & $80 \mathrm{mmHg}$ \\
\hline NH & 8 & $0.75 \pm 0.25$ & $1.25 \pm 0.25$ & $2.00 \pm 0.27$ & $2.25 \pm 0.25$ \\
NMS + RS & 8 & $1.13 \pm 0.30$ & $2.63 \pm 0.32^{\mathrm{a}}$ & $3.00 \pm 0.27^{\mathrm{b}}$ & $3.25 \pm 0.25^{\mathrm{b}}$ \\
High dose & 8 & $1.00 \pm 0.27$ & $1.5 \pm 0.33^{\mathrm{d}}$ & $2.00 \pm 0.27^{\mathrm{d}}$ & $2.38 \pm 0.38^{\mathrm{d}}$ \\
Middle dose & 8 & $1.00 \pm 0.27$ & $1.38 \pm 0.32^{\mathrm{d}}$ & $2.13 \pm 0.35^{\mathrm{d}}$ & $2.38 \pm 0.32^{\mathrm{d}}$ \\
Low dose & 8 & $1.00 \pm 0.27$ & $1.88 \pm 0.40$ & $2.88 \pm 0.30^{\mathrm{b}}$ & $3.25 \pm 0.25^{\mathrm{b}}$ \\
Pinaverium bromide & 8 & $1.00 \pm 0.27$ & $1.38 \pm 0.32^{\mathrm{d}}$ & $2.00 \pm 0.27^{\mathrm{d}}$ & $2.25 \pm 0.25^{\mathrm{d}}$ \\
\hline
\end{tabular}

${ }^{a} P<0.01,{ }^{b} P<0.05$, versus the normal control (no handling $[\mathrm{NH}]$ ) group.

${ }^{\mathrm{c}} \mathrm{P}<0.01,{ }^{\mathrm{d}} \mathrm{P}<0.05$, versus the neonatal maternal separation (NMS) + restraint stress (RS) group.

Data are expressed as the mean $\pm \mathrm{SE}$ ( $\mathrm{n}=8$ rats/group).

A

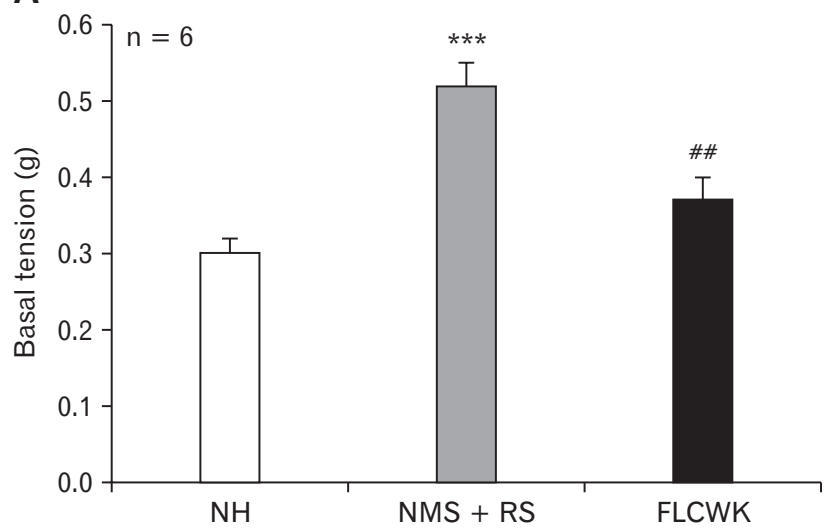

B

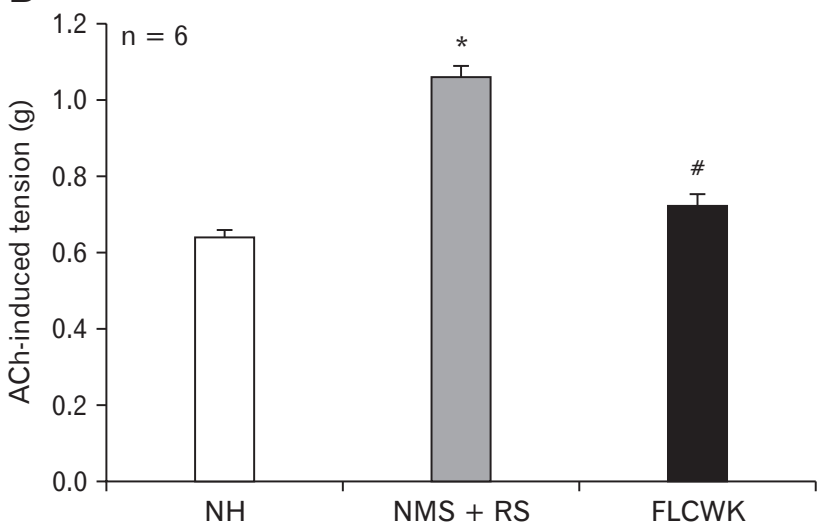

Figure 2. Comparison of basic tension and acetylcholine (ACh)-induced tension of colonic longitudinal smooth muscle strips (CLSMs) among the 3 groups (means $\pm \mathrm{SE}, \mathrm{n}=6$ ). (A) Basic tension. (B) ACh-induced tension. ${ }^{*} P<0.05$, ${ }^{* *} P<0.001$ versus normal control (no handling $[\mathrm{NH}]$ ) group; ${ }^{\#} P<0.05,{ }^{\# \#} P<0.01$, versus neonatal maternal separation (NMS) + restraint stress (RS) group. FLCWK, Fengliao-Changweikang $(2.25 \mathrm{mg} / 100 \mathrm{~g})$. 
were significantly decreased compared with the NMS + RS group ( $\mathrm{n}=6$; basic tension, $P<0.01$; ACh-induced tension, $P<0.05$; Fig. 2). In addition, no significant difference was found in basic tension and ACh-induced tension of CLSMs between the NH group and FLCWK group.

\section{No significant differences in acetylcholine-induced tension after treatment with nifedipine or TMB-8}

After pre-treatment of nifedipine $(10 \mu \mathrm{mol} / \mathrm{L})$ or TMB-8 $(20$ $\mu \mathrm{mol} / \mathrm{L}$ ) and equilibrated for 30 minutes, $10^{-4} \mathrm{~mol} / \mathrm{L} \mathrm{ACh}$ was added to CLSMs to induce muscle contraction, the tension of contractile response among the 3 groups was no significant differences $(\mathrm{n}=6, P>0.05$; Fig. 3$)$.

No significant differences in acetylcholine-induced tension after treatment with methylene blue or L-NAME

After pre-treatment with L-NAME (100 $\mu \mathrm{mol} / \mathrm{L})$ or methylene blue $(10 \mu \mathrm{mol} / \mathrm{L})$, no significant difference in ACh-induced tension of CLSMs was found among 3 groups $(n=6, P>0.05$; Fig. 4).

\section{No significant differences in acetylcholine-induced} tension after treatment with 4-AP

There was no statistical difference in ACh-induced tension of

A

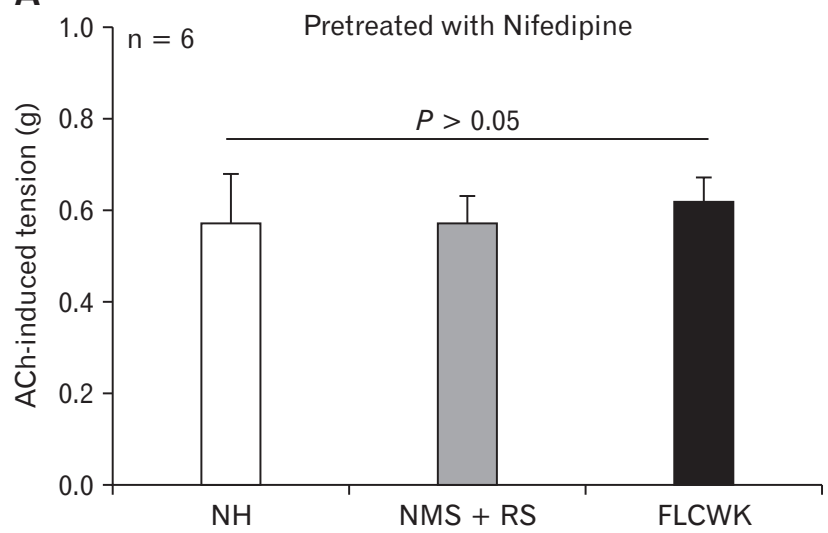

B

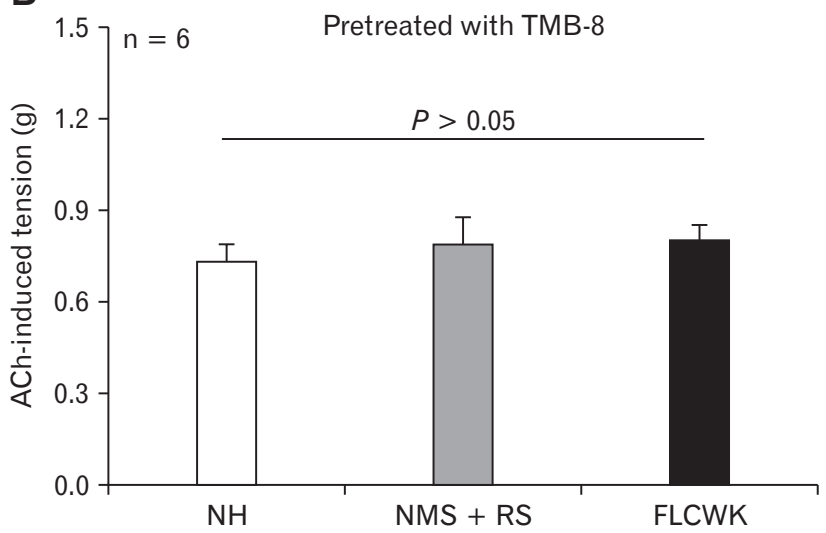

Figure 3. Comparison of acetylcholine (ACh)-induced tension of colonic longitudinal smooth muscle strips (CLSMs) after nifedipine (inhibitor of L-type voltage-depended $\mathrm{Ca}^{2+}$ channel) and TMB-8 (inhibitor of calcium release) (means $\pm \mathrm{SE}, \mathrm{n}=6$ ). (A) Pretreated with nifedipine. (B) Pretreated with TMB-8. NH, normal control (no handling); MMS, neonatal maternal separation; RS, restraint stress; FLCWK, FengliaoChangweikang $(2.25 \mathrm{mg} / 100 \mathrm{~g})$.

A

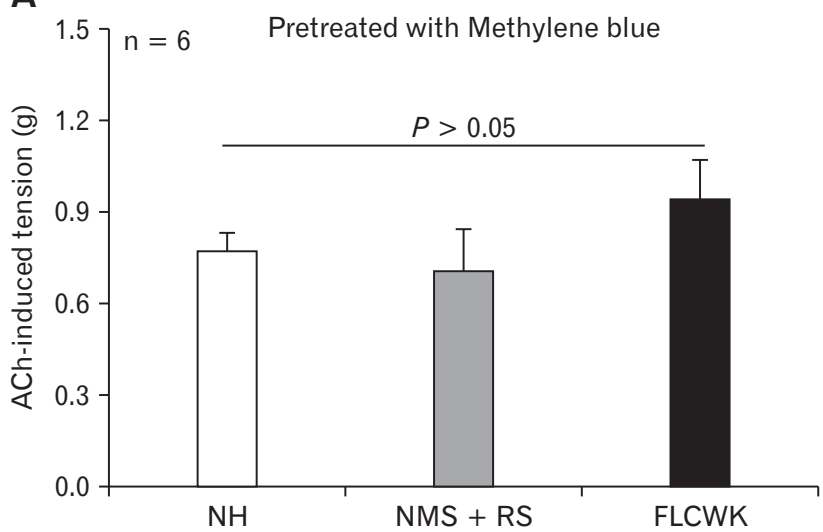

B

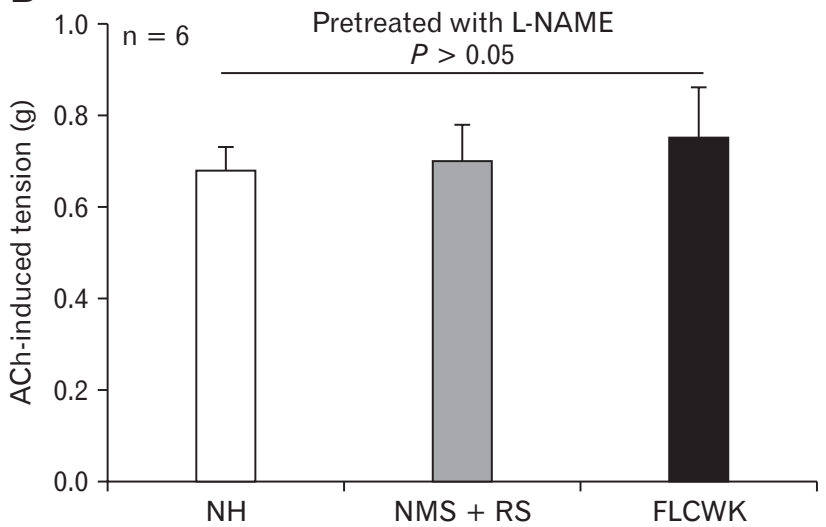

Figure 4. Comparison of acetylcholine (ACh)-induced tension of colonic longitudinal smooth muscle strips (CLSMs) after methylene blue (inhibitor of guanylate cyclase) and L-NAME (inhibitor of nitric oxide synthase) (means $\pm \mathrm{SE}, \mathrm{n}=6$ ). (A) Pretreated with methylene blue. (B) Pretreated with L-NAME. NH, normal control (no handling); MMS, neonatal maternal separation; RS, restraint stress; FLCWK, FengliaoChangweikang $(2.25 \mathrm{mg} / 100 \mathrm{~g})$. 


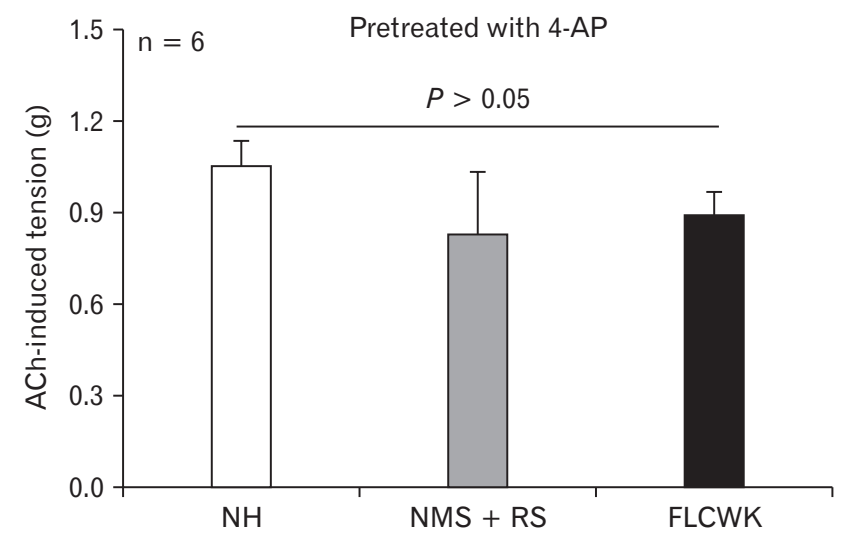

Figure 5. Comparison of acetylcholone (ACh)-induced tension of CLSMs after 4-AP (inhibitor of voltage dependent $\mathrm{K}^{+}$channel) (means $\pm \mathrm{SE}, \mathrm{n}=6$ ). $\mathrm{NH}$, normal control (no handling); MMS, neonatal maternal separation; RS, restraint stress; FLCWK, FengliaoChangweikang $(2.25 \mathrm{mg} / 100 \mathrm{~g})$.

CLSMs among 3 groups after treatment with 4-AP $(50 \mu \mathrm{mol} / \mathrm{L})(\mathrm{n}=$ 6, $P>0.05$; Fig. 5).

\section{Discussion}

In the present study, we found that the FLCWK treatment produced a therapeutic effect in IBS-D rats. Physiologically, FLCWK inhibited colonic motility in IBS-D rats. Mechanistically, FLCWK modulated colonic motility via the $\mathrm{NO} / \mathrm{cGMP} / \mathrm{Ca}^{2+}$ signaling pathways and specific potassium $\left(\mathrm{K}^{+}\right)$channels. To the best of our knowledge, this was the first time to report the specific curative mechanisms of FLCWK for IBS-D in regulating intestinal motility.

Our present study indicated that FLCWK was effective in treating IBS-D in rats. Clinically, FLCWK was previously reported to improve the quality of life in IBS patients. ${ }^{12,13}$ According to Traditional Chinese Medicine, FLCWK mainly consists of $D$. calycinum and $P$. hydropiper which play a role of clearing heat, de-humidificating and eliminating stagnation and results in relief of symptoms of abdominal pain and diarrhea induced by multiple etiologies. ${ }^{13-15}$ A clinical study performed by Wu et $\mathrm{al}^{14}$ showed that FLCWK could significantly relieve abdominal pain and improve the stool property in IBS-D patients. In the present study, similar responses were found: fecal characteristics, and EMG and AWR responses to rectal distention were significantly ameliorated with FLCWK. Furthermore, the efficacy of FLCWK in treating IBS$\mathrm{D}$ in the present rodent study was comparable to that of Pinaverium bromide which is known to provide good therapeutic efficacy in
IBS (Tables 1 and 2, Fig. 1). ${ }^{32}$

IBS-D has been reported to involve multi-factorial pathophysiologies, including abnormal intestinal motility, visceral hypersensitivity, increased intestinal permeability, immune activation, altered microbiota, and disturbances in brain-gut interactions. ${ }^{1}$ As one of the most important mechanisms in IBS-D, motility disturbance in IBS patients has been well explored for decades. Significant differences in muscular tone were reported among different subtypes: higher in IBS-D and IBS-M but not in IBS-C compared with healthy individuals. ${ }^{33} \mathrm{~A}$ number of animal experiments also demonstrated that hypertensive contractions of intestinal smooth muscle may be important in producing main IBS-D symptoms. ${ }^{34-38}$ Similar increased colonic basic tension and motility were noted in the current rodent study (Fig. 2A).

In our present study, FLCWK decreased the basic tension of colonic longitudinal smooth muscle strips in IBS-D rats, suggesting that colonic motility was involved in the curative mechanism of FLCWK for IBS-D (Fig. 2A). Previously, FLCWK and its components were shown to induce intestinal smooth muscle relaxation, modify gastrointestinal (GI) intestinal transit in mice, and prevent castor oil-induced diarrhea. ${ }^{39-41}$ However, the specific pathway of modulating colonic motility had not been previously elucidated.

In order to reveal the potential mechanism of FLCWK for decreased muscle tension, we investigated the role of $\mathrm{Ca}^{2+}$. As we know, the intracellular $\mathrm{Ca}^{2+}$ homeostasis is the foundation for maintaining normal contraction and relaxation of smooth muscle. Elevation of $\mathrm{Ca}^{2+}$ in contraction is accomplished by $\mathrm{Ca}^{2+}$ entry from the ectoenzyme and/or intracellular release of $\mathrm{Ca}^{2+}$ from the sarcoplasmic reticulum. The main route of calcium inward current is dependent on the L-type voltage-depended $\mathrm{Ca}^{2+}$ channel. ${ }^{42} \mathrm{Pi}$ naverium bromide, as the positive control drug in our experiment, has been shown to regulate the stress-induced colonic hypermotility and inhibit the contractile response to various kinds of agonists in vitro by blocking the L-type $\mathrm{Ca}^{2+}$ channel. ${ }^{29,43}$ Consistently, our present study revealed that FLCWK was also able to regulate colonic motility (Fig. 2A). We observed that ACh increased tension of CLSMs in each group and found that Ach-induced tension was decreased after the FLCWK treatment (Fig. 2B). ACh is known to result in muscle contractions by inducing the influx and release of $\mathrm{Ca}^{2+}$; hence we hypothesized that the decreased ACh-induced tension by FLCWK might be mediated by the $\mathrm{Ca}^{2+}$ signaling pathway. Further, we used the inhibitor of L-type voltage-depended $\mathrm{Ca}^{2+}$ channel, Nifedipine and intracellular calcium antagonist, TMB-8, and found no significant difference in ACh-induced tension of CLSMs between the FLCWK group and the NMS + RS 
group, which further confirmed the role of $\mathrm{Ca}^{2+}$ in the therapeutical effect of FLCWK (Fig. 3).

We further hypothesized that FLCWK regulates the $\mathrm{Ca}^{2+}$ flow through $\mathrm{NO} / \mathrm{cGMP}$ the pathway. It is well known that the pathway of $\mathrm{NO} / \mathrm{cGMP}$ contributes to the regulation of GI muscle contraction by regulating the $\mathrm{Ca}^{2+}$ influx process. $\mathrm{NO}$ is a major inhibitory enteric neurotransmitter that produces cGMP via activation of soluble guanylate cyclase. Then cGMP as a second signal transduction messenger mediates the GI smooth muscles relaxation. ${ }^{44,45}$ In our study, there were significant differences in Ach-induced tension of CLSMs among the groups. However, after treatment with L-NAME (an inhibitor of nitric oxide synthase) or methylene blue (an inhibitor of guanylate cyclase), the ACh-induced tension of CLSMs showed no difference between the FLCWK group and the NMS+RS group, suggesting that FLCWK decreased colonic activity via the NO/cGMP signaling pathway (Fig. 4). This hypothesized pathway was supported by modern researches, some ingredients of FLCWK regulated smooth muscle by similar mechanisms, such as rutin and quercetin inhibiting the smooth muscle via the NO signaling pathways. ${ }^{46-50}$

Similarly, $\mathrm{K}^{+}$channels also play a major role in the curative mechanism of FLCWK for IBS-D. The diversity of $\mathrm{K}^{+}$channels described in GI smooth muscles mainly includes voltage-gated $\mathrm{K}^{+}$ channels, $\mathrm{K}_{\mathrm{A}}$ channels, calcium-activated $\mathrm{K}^{+}$channels, and ATPsensitive $\mathrm{K}^{+}$channels. ${ }^{51}$ However, voltage-gated $\mathrm{K}^{+}$channels were considered the basis for the regulation of cell resting potential. ${ }^{52} \mathrm{In}$ our study, under normal conditions, the basic tension of CLSMs in NMS + RS group was significantly higher than the FLCWK group. Interestingly, after pre-treatment of 4-AP, a voltage dependent $\mathrm{K}^{+}$channel blocker, no statistical difference was found in ACh-induced tension of CLSMs in all groups (Fig. 5). Thus, we believe that FLCWK inhibited colonic contractions by regulating the specific potassium channels.

The present study has the following limitations: firstly, the expression of each molecular in the pathway and how each link performed were unclear, and further explore was needed. Secondly, we have not studied the potential mechanism of FLCWK in colonic motility of female rats for IBS-D. The reasons the female rats have been excluded in our study is to prevent potential effects of estrogen in motility regulation.

Our results suggest that FLCWK was effective in treating IBS-D in rats, which proved by improving fecal indexes, electromyographic recordings and AWR scores. Increased tension of CLSMs in NMS + RS group and meliorative tension of CLSMs in FLCWK group were investigated, which contributes to explore the role of colonic motility in the curative mechanism of FLCWK for IBS-D. Further, we studied the difference of ACh-induced tension in each group after treatment of inhibitors related to $\mathrm{NO} /$ cGMP $/ \mathrm{Ca}^{2+}$ and $\mathrm{K}^{+}$channel. Subsequently, no statistical difference was found in ACh-induced tension of CLSMs in all groups, suggesting that FLCWK inhibited colonic contractions via regulating $\mathrm{NO} / \mathrm{cGMP} / \mathrm{Ca}^{2+}$ and specific $\mathrm{K}^{+}$channels.

In conclusion, the therapeutic mechanism of FLCWK for IBS-D may be achieved by regulating colonic motility via the $\mathrm{NO} / \mathrm{cGMP} / \mathrm{Ca}^{2+}$ pathway and specific $\mathrm{K}^{+}$channels. Our findings provide direct evidence to help understanding the underlying therapeutic mechanism of FLCWK for IBS-D and promoting the application of FLCWK on a larger scale.

Financial support: This study was supported by the National Natural Science Foundation of China (Grant No. 81473644) and the Clinical Medicine Development Project of Beijing Municipal Administration of Hospitals (Grant No. ZYLX201411).

\section{Conflicts of interest: None.}

Author contributions: Mengdi Jia and Xiaofang Lu performed experiments, analyzed data, prepared figures, and drafted the manuscript; Luqing Zhao and Zhengfang Wang analyzed data, and drafted the manuscript; and Shengsheng Zhang designed and supervised the experiments and edited the manuscript.

\section{References}

1. Mearin F, Lacy BE, Chang L, et al. Bowel disorders. Gastroenterology 2016;150:1393-1407, e5.

2. Lovell RM, Ford AC. Global prevalence of and risk factors for irritable bowel syndrome: a meta-analysis. Clin Gastroenterol Hepatol 2012;10:712-721, e4.

3. Xin Y, Yun SY, Li HC, et al. Subtypes of irritable bowel syndrome on Rome III criteria: a multicenter study. J Gastroenterol Hepatol 2012;27:760-765.

4. Singh P, Staller K, Barshop K, et al. Patients with irritable bowel syndrome-diarrhea have lower disease-specific quality of life than irritable bowel syndrome-constipation. World J Gastroenterol 2015;21:81038109

5. Bellini M, Gambaccini D, Stasi C, et al. Irritable bowel syndrome: a disease still searching for pathogenesis, diagnosis and therapy. World J Gastroenterol 2014;20:8807-8820.

6. Efskind PS, Bernklev T, Vatn MH. A double-blind placebo-controlled trial with loperamide in irritable bowel syndrome. Scand J Gastroenterol 1996;31:463-468.

7. Wong BS, Camilleri M, Carlson P, et al. Increased bile acid biosynthesis 
is associated with irritable bowel syndrome with diarrhea. Clin Gastroenterol Hepatol 2012;10:1009-1015, e3.

8. Chang L, Lembo A, Sultan S. American gastroenterological association institute technical review on the pharmacological management of irritable bowel syndrome. Gastroenterology 2014;147:1149-1172, e2 .

9. Wade PR, Palmer JM, McKenney S, et al. Modulation of gastrointestinal function by $\mathrm{Mu}$ Delta, a mixed mixed $\mu$ opioid receptor agonist/ mixed $\mu$ opioid receptor antagonist. Br J Pharmacol 2012;167:11111125.

10. Spiller R, Aziz Q, Creed F, et al. Guidelines on the irritable bowel syndrome: mechanisms and practical management. Gut 2007;56:17701798.

11. Lesbros-Pantoflickova D, Michetti P, Fried M, Beglinger C, Blum AL. Meta-analysis: the treatment of irritable bowel syndrome. Aliment Pharmacol Ther 2005;20:1253-1269.

12. Mazurak N, Broelz E, Storr M, Enck P. Probiotic therapy of the irritable bowel syndrome: why is the evidence still poor and what can be done about it? J Neurogastroenterol Motil 2015;21:471-485.

13. Zhong HY, Liang J, Fan Y. Clinical observation of maple polygonum gastrointestinal capsule in the treatment of IBS. Hei Long Jiang Medicine and Pharmacy 2013;36:43-44.

14. Wu W, Guo F, Zhang FH. [Efficacy of Fengliao Changweikang granule on diarrhea type of irritable bowel syndrome and its effect on serum interleukin-17 and interleukin-23.] Chin J Clin Pharmaco 2015;31:621-623. [Chinese]

15. Liu MS, Liu C, Zhang XP, Yuan Z. [Chemical constituents of compound Changweikang.] Modernization of Traditional Chinese Medicine and Materia Medica-World Science and Technology 2010;12:614-616. [Chinese]

16. Liu MS, Guo XM, Zhang JP, et al. [Flavonoids from prescription Changweikang. Chemical constituents of compound Changweikang.] Modernization of Traditional Chinese Medicine and Materia MedicaWorld Science and Technology 2010;5:811-813. [Chinese]

17. Söderholm JD, Yates DA, Gareau MG, Yang PC, MacQueen G, Perdue $\mathrm{MH}$. Neonatal maternal separation predisposes adult rats to colonic barrier dysfunction in response to mild stress. Am J Physiol Gastrointest Liver Physiol 2002;283:G1257-G1263.

18. Ren TH, Wu J, Yew D et al. Effects of neonatal maternal separation on neurochemical and sensory response to colonic distension in a rat model of irritable bowel syndrome. Am J Physiol Gastrointest Liver Physiol 2007;292:849-856.

19. Lee JH, Kim JY, Jahng JW. Highly palatable food during adolescence improves anxiety-like behaviors and hypothalamic-pituitary-adrenal axis dysfunction in rats that experienced neonatal maternal separation. Endocrinol Metab 2014;29:169-178.

20. Larauche M, Mulak A, Taché Y. Stress-related alterations of visceral sensation: animal models for irritable bowel syndrome study. J Neurogastroenterol Motil 2011;17:213-234.

21. Xu JR, Luo JY, Shang L, Kong WM. Effect of change in an inhibitory neurotransmitter of the myenteric plexus on the pathogenetic mechanism of irritable bowel syndrome subgroups in rat models. Chin J Dig Dis 2006;7:89-96.
22. van Zyl PJ, Dimatelis JJ, Russell VA. Behavioural and biochemical changes in maternally separated sprague-dawley rats exposed to restraint stress. Metab Brain Dis 2016;31:121-133.

23. Xu SY, Bian RL, Chen X. Experimental methodology of pharmacology. Beijing: People's Medical Publishing House 2002.

24. Ma TM, Xu N, Ma XD, Bai ZH, Tao X, Yan HC. Moxibustion regulates inflammatory mediators and colonic mucosal barrier in ulcerative colitis rats. World J Gastroenterol 2016;22:2566-2575.

25. Winston J, Shenoy M, Medley D, Naniwadekar A, Pasricha PJ. The vanilloid receptor initiates and maintains colonic hypersensitivity induced by neonatal colon irritation in rats. Gastroenterology 2007;132:615-627.

26. Al-Chaer ED, Kawasaki M, Pasricha PJ. A new model of chronic visceral hypersensitivity in adult rats induced by colon irritation during postnatal development. Gastroenterology 2000;119:1276-1285.

27. Xue H, Tian YM, Yan M, et al. Appearance of segmental discrepancy of anion transport in rat distal colon. Biol Pharm Bull 2007;30:1407-1411.

28. Saito YA, Strege PR, Tester DJ, et al. Sodium channel mutation in irritable bowel syndrome: evidence for an ion channelopathy. Am J Physiol Gastrointest Liver Physiol 2009;296:G211-G218.

29. Chen Y, Li Z, Yang Y, Kin L, Zhang H. Role of glucagon-like peptide-1 in the pathogenesis of experimental irritable bowel syndrome rat models. Int J Mol Med 2013;31:607-613.

30. Qin QG, Wang HP, Liu K, et al. Effect of acupuncture at ST25 on intestinal motility in normal rats, diarrhea and constipation model rats. World Chin Med 2013;8:245-249.

31. Zhang S, Jiao T, Chen Y, Gao N, Zhang L, Jiang M. Methylglyoxal induces systemic symptoms of irritable bowel syndrome. PLoS One 2014;9:e105307.

32. Dai Y, Liu JX, Li JX, Xu TF. Effect of pinaverium bromide on stressinduced colonic smooth muscle contractility disorder in rats. World J Gastroenterol 2003;9:557-561.

33. Kanazawa M, Palsson OS, Thiwan SI, et al. Contributions of pain sensitivity and colonic motility to IBS symptom severity and predominant bowel habits. Am J Gastroenterol 2008;103:2550-2561.

34. Collins SM. Peripheral mechanisms of symptom generation inirritable bowel syndrome. Can J Gastroenterol Hepatol 2001;15(suppl B):14B$16 \mathrm{~B}$.

35. Yang C, Zhang SS, Li XL, Wang ZF, Zhao LQ. Inhibitory effect of tong xie-yao fang formula on colonic contraction in rats. World J Gastroenterol 2015;21:2912-2917.

36. Park JH, Rhee PL, Kim HS, et al. Mucosal mast cell counts correlate with visceral hypersensitivity in patients with diarrhea predominant irritable bowel syndrome. J Gastroenterol Hepatol 2006;21(1 Pt 1):71-78.

37. Lee OY. Asian motility studies in irritable bowel syndrome. J Neurogastroenterol Motil 2010;16:120-130.

38. Zhong L, Hou X. Pathophysiologic findings of irritable bowel syndrome in china. J Neurogastroenterol Motil 2012;18:19-33.

39. Hammad HM, Abdalla SS. Pharmacological effects of selected flavonoids on rat isolated ileum: structure-activity relationship. Gen Pharmacol 1997;28:767-771.

40. Ren SZ, Liang X, Su WQ, Wang N, Chen J, Ma ZJ. [Study on the materialbasis of anti-inflammatory anti-diarrhea effect of Fengliao ex- 
tract.] Loshizhen Medicine and Meteria Medica research 2016;27:3234. [Chinese]

41. Gálvez J, Crespo ME, Jiménez J, Suárez A, Zarzuelo A. Antidiarrhoeic activity of quercitrin in mice and rats. J Pharm Pharmacol 1993;45:157159 .

42. Sanders KM. Invited review: mechanisms of calcium handling in smooth muscles. J Appl Physiol 2001;91:1438-1449.

43. Malysz J, Farraway LA, Christen MO, Huizinga JD. Pinaverium acts as L-type calcium channel blocker on smooth muscle of colon. Can J Physiol Pharmacol 1997;75:969-975.

44. Altdorfer K, Bagaméri G, Donáth T, Fehér E. Nitric oxide synthase immunoreactivity of interstitial cells of cajal in experimental colitis. Inflamm Res 2002;51:569-571.

45. Groneberg D, König P, Koesling D, Friebe A. Nitric oxide-sensitive guanylyl cyclase is dispensable for nitrergic signaling and gut motility in mouse intestinal smooth muscle. Gastroenterology 2011;140:1608-1617.

46. Matsumoto T, Horiuchi M, Kamata K, Seyama Y. Effects of bidens pilosa L. var. radiata SCHERFF treated with enzyme on histamineinduced contraction of guinea pig ileum and on histamine release from mast cells. J Smooth Muscle Res 2009;45:75-86.
47. Yang Z, Pan A, Zuo W, Guo J, Zhou W. Relaxant effect of flavonoid naringenin on contractile activity of rat colonic smooth muscle. J Ethnopharmacol 2014;155:1177-1183.

48. Gim H, Nam JH, Lee S, et al. Quercetin inhibits pacemaker potentials via nitric oxide/cGMP-dependent activation and TRPM7/ANO1channels in cultured interstitial cells of cajal from mouse small intestine. Cell Physiol Biochem 2015;35:2422-2436.

49. Li W, Chen Z, Yan M, He P, Chen Z, Dai H. The protective role of isorhamnetin on human brain microvascular endothelial cells from cytotoxicity induced by methylglyoxal and oxygen-glucose deprivation. J Neurochem 2016;136:651-659.

50. Huo Y, Yi B, Chen M, et al. Induction of Nur77 by hyperoside inhibits vascular smooth muscle cell proliferation and neointimal formation. Biochemical Pharmacology 2014;92:590-598.

51. Xiong Z, Sperelakis N, Noffsinger A, Fenoglio-Preiser C. Potassium currents in rat colonicsmooth muscle cells and changes during development and aging. Pflugers Arch 1995;430:563-572.

52. Thornbury KD, Ward SM, Sanders KM. Participation of fast-activating, voltage-dependent $\mathrm{K}$ currents in electrical slow waves of colonic circular muscle. Am J Physiol 1992;263(1 Pt 1):C226-C236. 